\title{
Visit, Revisit, or Stay Longer? A Case of Emerging Tourism Destination
}

Shahren Ahmad Zaidi Adruce

i-CATS University College, Sarawak, Malaysia

Hiram Ting

Faculty of Hospitality and Tourism Management, UCSI University, Malaysia

Department of Leisure and Recreation Management, Ming Chuan University, Taiwan

Puah Chin Hong*

Faculty of Economics and Business, Universiti Malaysia Sarawak, Malaysia

\section{Lim Tze-Yin}

Faculty of Business, Design and Arts, Swinburne University of Technology,

Sarawak Campus, Malaysia

\section{Sherrymina Kichin}

Department of Tourism and Commerce, UCSI University, Malaysia

*Corresponding author: chpuah@unimas.my

\begin{abstract}
Despite substantial extant literature on tourists' visiting behavior, little is known about the intention to visit, revisit, and stay longer in an emerging destination. Sarawak is an emerging destination that has demonstrated the capability to attract tourists from China. The present study lays the groundwork for the exploration of Chinese tourists' main motives to visit, revisit, and stay longer in Sarawak based on push and pull factors. A qualitative research design was adopted, following which 355 interviews were conducted over two stages of data collection. All transcriptions were then analyzed using thematic analysis. The findings revealed three categories related to the intention to visit Sarawak, namely "China residents who have not been to Sarawak", "China residents who have been to Sarawak", and "China residents who consider having a longer stay in Sarawak". In addition, the pull and push factors influencing their visiting intention were assessed. This case study offers an explanatory model that informs local stakeholders on the significant motivation factors that attract Chinese tourists to Sarawak. From a managerial standpoint, local agencies, tourism promoters, and marketers could expend more resources to advertise Sarawak's attractions, such as ethnic food, festivals, multi-cultural heritage, adventures, and nature.
\end{abstract}

Keywords: Emerging destination, Visit intention, Push and pull factor, China, Stay longer

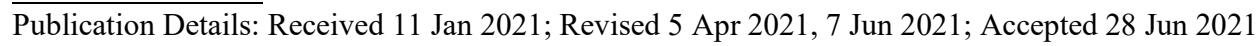




\section{Background}

The rise of Asian tourism has received growing attention from scholars in recent years, especially in the context of emerging destinations. The "emerging" concept is referred to as an activity exploring tourists' behavior and engagement in international tourism activities, or in other words, the investigation of tourist activities in a global context (King, 2017). Previous research has addressed geopolitical areas in which tourism activity contributes to economic development, with each destination demonstrating distinct characteristics and stages (Esu and Ebitu, 2010). Notably, the most substantial growth of tourism in the next decade is expected to be in Asia, as per a survey by the UNWTO. In fact, the number of international tourists visiting ASEAN countries is equivalent to the world's popular destinations, such that the Asian tourism industry is considered one of the most significant areas to intensify the attractiveness and uniqueness of countries in the region (The World Bank, 2014). In 2018, 128.7 million international tourists visited countries in Southeast Asia, contributing 121 billion Euros to the region's Gross Domestic Product (GDP) and creating employment opportunities for 38.1 million people (UNWTO, 2019). Notably, Malaysia received more than half of all international tourist visits to the region (Trupp and Dolezal, 2020; WTTC, 2019). Indeed, Malaysia is a popular destination for travel and leisure in the ASEAN region (Seow et al., 2017).

In addition, the growing tourist segment from China is expected to lead the way in the Asian tourism market due to the rise of the Chinese middle-class, who have strong spending power and consumption trends (Dai et al., 2017; Mandal and Vong, 2016). Previous studies have estimated that China will be one of the drivers of tourism in ASEAN, with the number of Chinese tourists projected to reach 200 million in the year 2030, constituting a massive portion of the tourist population for ASEAN countries (Nugroho, 2017). This follows the Chinese government's selection of a few ASEAN countries in 1990 as approved tourist destinations for Chinese tourists, Malaysia being one of them (Rosyidi, 2018). Nevertheless, studies on Chinese tourists' intention to visit, revisit, and stay longer in an emerging destination are relatively scarce. Instead, most extant literature emphasizes Chinese tourists' behavioral responses to motivation factors, socio-economic factors, and political influence in different national contexts (Lai et al., 2018; Piuchan et al., 2018; Rosyidi, 2018).

People visit, revisit and intend to stay longer in a place for several different purposes. This study explores the tourist's intention to visit an emerging destination by assessing the intention to visit, revisit, and stay longer; the findings are discussed together with the push and pull factors as a proposed framework in the study. Previous tourism research has mainly addressed the factors influencing the intention to visit or revisit a country (Çelik and Dedeoğlu, 2019; Chen et al., 2017, Khuong and Nguyen, 2017), with intention considered to be a predictor of tourists' first-time and recurrent behaviors (Ajzen, 1991). Accordingly, destination image, satisfaction, destination quality, travel motivation, and customer satisfaction have been associated with travel behavior to a destination (Chang et al., 2017; Khan et al., 2017, Prayag et al., 2018; Wong et al., 2013). Additionally, scholars have studied the antecedents to tourists' revisit intention to the same country to understand the motivation behind such behavior ( $\mathrm{Li}$ and Ying, 2018; Meleddu et al., 2015). 
The literature concurs that push factors define tourism demand and are related to intangible features, such as the inherent desires and socio-psychological motives of travelers (Baniya and Paudel, 2016). These intangible characteristics include tourists' desire for novelty, rest, knowledge, and relaxation, which ultimately affect their behavior (Dolinting et al., 2015). Pull factors, on the other hand, attract tourists to a place and are related to a specific destination's tangible characteristics (Fam et al., 2017). The beauty of a location, scenic attractions, events, and natural landscapes are among the pull factors that influence travelers' decision-making process (Kim et al., 2012). Substantial tourism studies have focused on push and pull factors to determine tourists' motivations to visit and revisit a place and thereby develop suitable tourism marketing strategies (Baniya and Paudel, 2016; Dolinting et al., 2015; Fam et al., 2017; Yousefi and Marzuki, 2015). However, limited research has discussed tourists' visiting intention by combining the three types of behavioral intentions (visit, revisit, and stay longer), especially in the context of emerging destinations, although people visit, revisit, and intend to stay longer in a place for different purposes.

In the present years, Asia has served as an emerging destination in attracting international tourists. In 2018, 128.7 million international tourists have visited the countries in Southeast Asia and contributed Euro 121 billion to the region's Gross Domestic Product (UNWTO, 2019). Such activities also open up significant employment opportunities employing 38.1 million people, and Malaysia, as one of the emerging destinations, has also received more than half of all international tourist visits in the region (Trupp, and Dolezal, 2020; WTTC, 2019). In addition, the prior research literature has addressed that China will be one of the drivers of world tourism in ASEAN, with estimated Chinese tourists of 200 million travelers in the year 2030 (Nugroho, 2017). Nevertheless, the studies about the Chinese visiting intention to visit, revisit and stay longer in Sarawak as an emerging destination is relatively unknown. Most of the extant literature focuses on studying Chinese tourist's behavior towards the motivation factors, socio-economic factors, and political influence in different country contexts (Lai, et al., 2018; Piuchan, Chan and Kaale, 2018; Rosyidi, 2018).

In ASEAN, Malaysia is a popular destination for traveling and vacation (Seow, Choong, Moorthy and Chan, 2017). Previous literature demonstrated that tourism activity has transformed into a global relaxation action, especially for Malaysia, Thailand, Lebanon, Egypt, Spain, and Greece (Khan, et al., 2013). The tourism industry had contributed RM19.4 billion worth of investment, and it offered 1.77 million jobs in the tourism industry (Theobald, 1995). The tourist's expenditure on goods and services contributed approximately seven percent of total world export receipts and 4.6 percent of the world's national income (World Tourism Organization, 2017). As one of the emerging tourism destinations in Malaysia, Sarawak is a union of colonial and mixed societies from both Asian and European backgrounds. Bordering Brunei and Indonesia, the state is located on the island of Borneo and is the largest Malaysian state by size. Notably, Sarawak's rich historical and cultural background is unique and distinctive (Ting et al., 2019). Despite extensive literature on tourism in Sarawak, gaps still exist from a different perspective. Specifically, though scholars have addressed the factors influencing tourists' visit intention and consumption behavior, little is known about tourists' intention to visit, revisit, and stay longer in Sarawak (Chin et al., 2018; Fam et al., 2020; Sinvadasan, 2017: Ting et al., 2019). Therefore, this study explored Chinese tourists' intention to visit, revisit, and extend their stay at the emerging destination of Sarawak with regard to push and pull factors. 
The current study aimed to fill the aforementioned literature gaps by exploring Chinese tourists' visit intention to Sarawak as an emerging destination, based on the influence of push and pull factors. Accordingly, three research questions were formulated to guide this exploratory study, as follows:

1. What are the push and pull factors affecting Chinese tourists' intention to visit Sarawak as an emerging destination?

2. What are the push and pull factors affecting Chinese tourists' intention to revisit Sarawak as an emerging destination?

3. What are the push and pull factors affecting Chinese tourists' intention to stay longer in Sarawak as an emerging destination?

The current study offers a new perspective for practitioners and policymakers pertaining to the importance of emerging tourism destinations for growing tourist segments, since little attention has been paid to Chinese tourists' visit intention to Sarawak. In addition, this study provides insights into the push and pull factors that attract Chinese tourists to travel, thus enabling effective and suitable strategic planning from the managerial perspective. It also proposes recommendations for the sustainable development of Sarawak's tourism sector, given that creating a sustainable tourism environment requires fulfilling customers' satisfaction and positive experiences. To enrich the existing literature, the present study's findings provide an explanatory model that addresses the critical pull and push factors affecting tourists' behavior in an emerging destination.

\section{Methodology}

\section{Research Design}

As the current study intended to explore Chinese tourists' visit intention to an emerging destination, a qualitative research design was adopted. The constructivism paradigm was assumed, since the experiences shared by Chinese tourists are viewed as a social reality constructed through human interaction and experience (Chandra and Shang, 2017; Tsang, 2014). Previous literature has further confirmed that a qualitative study is appropriate to assess the interactions and experiences among a group of people or to obtain insights into particular social processes within a specific natural setting (Creswell and Poth, 2016; Ting et al., 2018). Therefore, the current study focused on the detailed interactions and realities behind Chinese tourists' visiting intention, as directed by push and pull factors.

\section{Data Collection}

There were two stages of the data collection in the current study. In the first stage, semistructured interviews via an online survey were conducted with 300 participants from China. Social media platforms, such as WeChat, were utilized to collect responses. In the second stage of data collection, 55 participants were interviewed face-to-face using open-ended and flexible probing questions to generate additional insights. Data from the second stage interviews was intended to triangulate the data obtained in the first stage for the purpose of enhancing the validity of the research. Scholars have stated that if findings across all a study's methods produce similar conclusions, validity is established (Guion et al., 2011; Natow, 2020). 
The target respondents comprised middle-class Chinese tourists, either employed or retired, with an average annual income of CNY50,000 to CNY500,000, because this segment has the ability and proclivity to travel. The purposive sampling technique was adopted to select respondents who met these predetermined criteria (Polit and Beck, 2012), as it would not have been possible to randomly choose each participant from a large population like that of China (Maxfield and Babbie, 2011). In terms of sampling size, there are no specific guidelines on the number of cases or participants in qualitative studies; however, reaching the point of data saturation is suggested (Corbin and Straus, 2014; Perry, 1998). Following this recommendation, a sample size of 355 adults was ultimately achieved over the two stages of data collection. All interviews were conducted in Mandarin and were audio-recorded and transcribed simultaneously (Kurasaki, 2000).

\section{Data Analysis}

The current study utilized semi-structured, open-ended questions to obtain insights from the participants. The textual data derived from the online survey and interview transcripts were transcribed verbatim and translated into a single language (English) by the researcher and coders. Quirkos, a powerful analytical software, was used to perform data sorting, coding, and organizing (Harvey and Powell, 2020). This software enabled the researchers to manage and understand the textual data by identifying connections between codes, themes, and categories (Basit, 2003). Thematic analysis and coding procedures using the grounded theory approach were then used to analyze the data. Thematic analysis is a method for identifying, analyzing, and reporting patterns (Braun and Clarke, 2006) that is deemed appropriate for textual data derived from interviews, where topics focus on an individual's thoughts and experiences (Joffe, 2012). The coding procedure began with a careful evaluation of the textual data, following which underlying concepts and clusters of concepts were carefully examined (Polit and Beck, 2012). Open coding was the first stage of coding analysis, where the researcher and coders read and examined the transcripts via the comparison of line to line reading (Corbin and Strauss, 2014). Accordingly, categories and subcategories were developed based on the codes that emerged in the open coding process. The final stage of coding involved the selective coding process, where themes and properties related to the discussion topic were finalized by the researcher and coders. The transcripts were then condensed into themes supported by inter-coder agreement and team coding (Saldana, 2021). Any discrepancies were resolved through multiple discussions and final consensus among the researcher and coders.

\section{Validation Check}

The current study conducted two stages of data collection, which allowed for the validation of the data through triangulation. Triangulation facilitates innovative ways to understand human interactions and experiences in a qualitative study by revealing data that integrates theories (Natow, 2020). In addition, inter-coder agreement was performed in exploring the insights shared by Chinese tourists. Inter-coder agreement is a crucial stage of qualitative data analysis. Prior studies have recommended that multiple researchers should perform coding to enhance inter-coder reliability in the analysis of interview data (Kurasaki, 2000). Accordingly, in this study, the researcher and coders reviewed and explored related codes and categories until an agreement was reached. Team coding with cross-checking at every session was also done to reach a 
confirmation and consensus on the selected codes and themes. No basic requirement of percentage was set to reach an agreement among team members (Saldana, 2021).

\section{Findings}

\section{Participants' Demographics}

Demographically, the sample had slightly more women than men. Most of the participants were below 25 years old and were students or working adults. Interestingly, a large majority of respondents had neither visited nor heard of Sarawak. Table 1.0 presents the participants' demographic profile.

Table 1: Respondents' Demographic Profile

\begin{tabular}{|c|c|c|c|}
\hline Variables & & Frequency & Percentage \\
\hline \multirow{2}{*}{ Gender } & Male & 172 & $48.45 \%$ \\
\hline & Female & 183 & $51.55 \%$ \\
\hline \multirow{8}{*}{ Age Group } & $<20$ & 58 & $16.34 \%$ \\
\hline & $21-25$ & 130 & $36.62 \%$ \\
\hline & $26-30$ & 56 & $15.77 \%$ \\
\hline & $31-35$ & 43 & $12.11 \%$ \\
\hline & $36-40$ & 21 & $5.92 \%$ \\
\hline & $41-45$ & 24 & $6.76 \%$ \\
\hline & 46 - so & 13 & $3.66 \%$ \\
\hline & 51 and above & 10 & $2.82 \%$ \\
\hline \multirow{5}{*}{ China Region } & Northeast & 14 & $3.94 \%$ \\
\hline & North & 91 & $25.63 \%$ \\
\hline & East & 156 & $43.94 \%$ \\
\hline & Central South & 18 & $5.07 \%$ \\
\hline & South & 32 & $9.01 \%$ \\
\hline \multirow{4}{*}{ Occupation } & Southwest & 33 & $9.30 \%$ \\
\hline & Northwest & 11 & $3.10 \%$ \\
\hline & Working Adults & 175 & $49.30 \%$ \\
\hline & Students & 169 & $47.61 \%$ \\
\hline \multirow{3}{*}{ Visited Malaysia } & $\begin{array}{l}\text { Others } \\
\text { (Housewife) }\end{array}$ & 11 & $3.10 \%$ \\
\hline & Yes & 89 & $25.07 \%$ \\
\hline & No & 266 & $74.93 \%$ \\
\hline Heard of & Yes & 94 & $26.48 \%$ \\
\hline Sarawak & No & 261 & $73.52 \%$ \\
\hline \multirow[t]{2}{*}{ Visited Sarawak } & Yes & 48 & $13.52 \%$ \\
\hline & No & 307 & $86.48 \%$ \\
\hline
\end{tabular}




\section{Themes of Chinese Tourists' Visit Intention to Sarawak}

Chinese tourists' intention to visit Sarawak, based on push and pull factors, was explored using thematic analysis. Three main themes emerged from the analysis and were categorized into three separate categories: 1) China residents who have not been to Sarawak; 2) China residents who have been to Sarawak; and 3) China residents who consider having a longer stay in Sarawak.

\section{Theme (1) China residents who have not been to Sarawak}

The findings suggest that most Chinese residents who have not been to Sarawak have never heard about Sarawak and do not even know its location as an emerging destination. The experiences shared by Chinese tourists indicated only a handful of information and uncertain awareness about the destination. Promotional activities regarding the destination are limited at best, since social media information on Sarawak appears to be lacking. In addition, knowledge about the state's cultural background and societal activities is unclear. This situation is evidenced in the following excerpts:

I do not know where Sarawak is and have never heard of such a place.

I am not aware of this city as there is a lack of promotion and marketing.

I am unsure on the local people's perception towards Chinese tourists, language barriers, and foods.

Neither my friends nor I have heard about this place.

I have been to Sabah; I never knew that Sarawak is just next to Sabah.

I have never heard about this city, so I choose not to travel there because I am concerned about my safety.

The scenery is beautiful with sandy beaches like Sabah. But I do not know how to travel there due to logistics issues.

Prior studies have indicated that most Chinese travelers depend on information from local authorities and other social media platforms. In fact, social media channels like WeChat, Sogou, QQ, and Baidu are widely used in China and are useful in promoting tourism activities (Yu, 2013; Zhou and Wang, 2014). Ultimately, Chinese tourists choose not to visit Sarawak since their awareness of the mentioned destination is low and they are unsure of the destination's image in terms of security. Hence, destination image and access to destination information are considered pull factors that influence Chinese tourists' intention to visit Sarawak.

\section{Theme (2) China residents who have been to Sarawak}

The second theme that emerged is Chinese tourists who have visited Sarawak. The tourists' interviews divulged several preferences and concerns upon visiting the destination. Their main concern pertains to the lack of promotional information and marketing materials by local authorities, which has left them with a low awareness level. Also, transportation and communication network problems are travel motivation factors that hinder their decision to revisit Sarawak. In a more positive light, Chinese tourists give credit to Sarawak as an emerging destination for its attractiveness and limited language barriers. 
The following quotes support this theme:

There is not much information and marketing material about this city.

There is no direct flight, and it is very troublesome.

The local tour agent did not promote this city, only Sabah and Genting Highlands.

There are not many interesting places available due to transportation and logistics issues.

In China, I seldom bring anything with me when I go out, except my mobile phone. All my payments can be made through a digital wallet on my mobile phone. Just scan, and it's done.

The city is beautiful, and the people over there are friendly.

It is a hometown of my friend; I have been there once. It is a beautiful city, and there are no language barriers.

\section{Theme (3) China residents who consider having a longer stay in Sarawak}

The third theme that emerged is the intention of Chinese tourists to stay for a longer period in Sarawak when they visit the destination. The findings show a lack of motivational or attractive factors that entice tourists to stay longer. Therefore, their intention to have an extended stay when visiting Sarawak was found to be relatively low. Pull and push factors such as destination image, destination information, security and safety issues, communication, infrastructure, and transportation were also cited as factors that deter their intention to stay longer. Tourists further mentioned that their peers greatly influence their intention to visit Sarawak. These excerpts by the participants illustrate these findings:

I think the city is lacking proper development and infrastructure. Hence, there are not enough interesting places and tourist spots to visit.

I could not find a travel package by a local travel agent to promote this city and its interesting places that really excites me to stay longer.

I wish to be there again or apply to be its citizen. China is too crowded and too competitive.

My friend shared with me some photos of her last visit. I am planning to visit this city next year and spend some time there because I think this city is truly beautiful.

A few of my friends live in Kuching. It makes me want to visit them someday as they keep telling me about its stable economy, beautiful scenery, nice food, zero air pollution, no massive traffic, and good living standards.

\section{Discussion}

Based on the findings, the current study proposes an explanatory framework (Strauss and Corbin, 1997) encompassing the visit, revisit, and extended stay intentions of Chinese tourists to Sarawak (See Figure 1). Such a framework is by no means conclusive. Nevertheless, it provides a holistic view of visit intention in three distinctive forms which, in turn, invites further investigation of behavioural intention to visit any emerging tourism destination.

The framework incorporates the three themes of intentions to visit, revisit, and stay longer in Sarawak (indicated in blue). Consumers' decision-making process, which includes their awareness, interest, feedback, and search (indicated in white) has been revealed to influence their intentions. The influence of push and pull factors (indicated 
in yellow), such as communication, information, and tour packages, have been addressed in the model as well. Lastly, the green boxes show moderating or facilitating conditions (e.g., online reviews, social influence, infrastructure, direct flights, etc.) that can weaken or strengthen Chinese tourists' decision-making and intention to visit or not visit the destination.

The current findings align with prior studies that have highlighted intention as an essential factor in predicting consumers' behaviors, including first-time and recurrent behaviors (Ajzen, 1991). The emergent themes suggest that Chinese tourists have three distinct behavioral intentions towards Sarawak, namely the intentions to visit, revisit, and stay longer. These intentions, in turn, are affected by push and pull factors that have been documented in the literature (e.g., Baniya and Paudel, 2016; Dolinting et al., 2015; Fam et al., 2017; Yousefi and Marzuki, 2015). Specifically, research has found that destination image, satisfaction, destination quality, travel motivation, security, and customer satisfaction affect tourists' behavior and intention to visit a destination (Khan et al., 2017, Chang et al., 2017; Prayag et al., 2018; Wong et al., 2013). In the present study, the themes depict that Chinese tourists have the intention to revisit or stay longer in Sarawak due to its attractiveness, scenic locations, events, and natural landscapes that act as the key motivational factors driving their decision-making process (Kim et al., 2012). However, the themes also explicitly show the factors that impede them from visiting, revisiting and staying longer. Both perspectives are equally important to Sarawak's development as an attractive tourism destination.

Moreover, the findings parallel the notion of 'pull factors' that attract tourists towards an actual destination choice (Bindu and Kanagaraj, 2013). As revealed in the case of Sarawak, accessibility to information on an emerging destination is crucial in influencing tourists' intention to visit it. In this regard, the effective use of internet networks, information technology, and social media would deliver information on tourist destinations and trigger individuals' decision-making process (Hudson and Thal, 2013; Yu, 2013). Apart from this, the current findings offer an alternative perspective on the roles of social groups and local policymakers in influencing Chinese travelers' visiting intentions. For instance, friends' sharing of Sarawak's beauty and attractions encourage tourists to visit, revisit, and stay longer in Sarawak. This concept is currently lacking in the literature, since most tourism studies focus only on pull and push factors (Chang et al., 2017; Prayag et al., 2018). 
Figure 1: Proposed Explanatory Framework

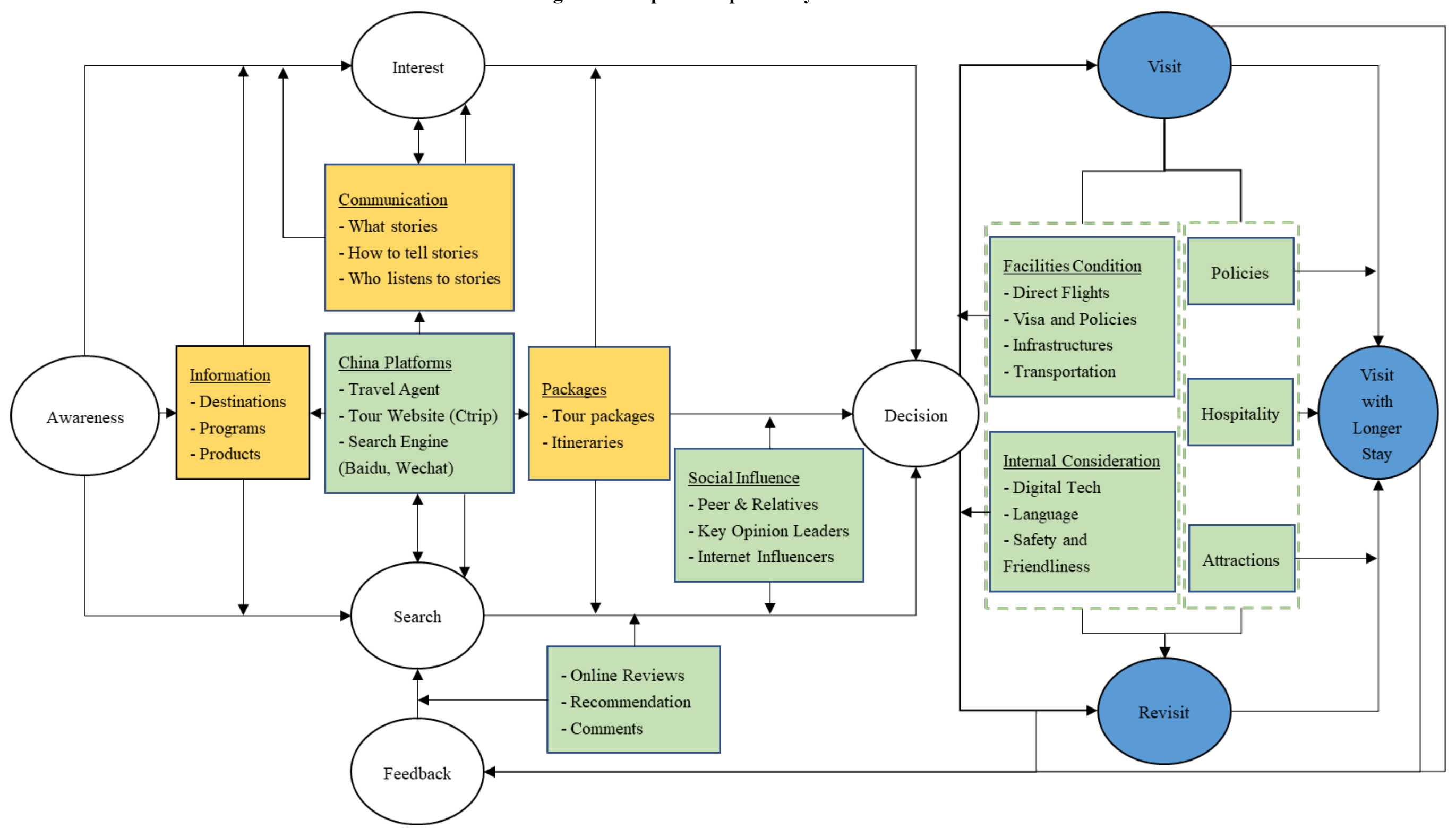




\section{Recommendations and Conclusion}

The present study extends the knowledge and scholarly interest on Chinese tourists' visit intentions to emerging destinations by elucidating that travelers visit, revisit and intend to stay longer in Sarawak due to various push and pull factors (Çelik and Dedeoğlu, 2019; Chen et al., 2017, Khuong and Nguyen, 2017). In particular, the findings that low perceptions and awareness of destination image, security and safety, infrastructure, travel motivation, and information access are discouraging tourists' travel intentions to Sarawak confirm extant research evidence on the importance of tangible (pull) and intangible (push) factors to predict consumers' first-time and recurrent behaviors (Ajzen, 1991; Baniya and Paudel, 2016; Fam et al., 2017). This study also highlights the need to concurrently explore the decision-making process behind three distinct behavioral intentions (visit, revisit, and stay longer), since previous studies have mostly examined only one specific visit intention (Baniya and Paudel, 2016; Dolinting et al., 2015; Fam et al., 2017; Yousefi and Marzuki, 2015). The proposed explanatory framework comprehensively depicts the internal decisionmaking process of travelers, as well as the external factors and facilitating conditions affecting their visit intentions. This valuable framework can and should be empirically tested in the future across different contexts and settings.

From the managerial perspective, the present study suggests the implementation of competitive strategies by policy makers, local authorities, and tourism service providers in Sarawak. Based on the findings, the authorities and government bodies must urgently improve marketing and promotional strategies to increase the brand awareness of Sarawak as an emerging destination in Asia. Collaborations can also be made with external parties to improve the accessibility of information through different communication channels. For instance, digital platforms such as Baidu, WeChat, and Weibo should be considered in promoting this emerging destination to Chinese tourists, since these social media channels have the greatest reach towards the target audience. Such "pull factors" enable Chinese tourists to visit and revisit Sarawak as an emerging destination, since interaction would be increased and communication would no longer be a barrier. Other than that, factors like cultural background, historical resources, security, and infrastructure development need to be reviewed and improved by the local authorities to enhance tourists' visiting intention. Focusing on marketing and promotional strategies as well as infrastructure development would facilitate the sustainable tourism growth of Sarawak as an emerging tourism destination.

Additionally, this study provides a new prospect for local stakeholders and policymakers to target tourists based on their characteristics. For instance, the current findings suggest diverse preferences among Chinese tourists with regards to their desire for unique, natural, and cultural attractions. Therefore, local stakeholders should introduce Sarawak's unique environment, natural scenery, and cultural heritage as a motivational 'pulls' for targeted tourists. In addition, the present study offers a pathway for local authorities and tourism service providers to look into potential tourism events that can attract inbound travelers from China. For example, food tourism, medical tourism, shopping tourism, and sports tourism are increasingly popular events that draw Chinese tourists. Moreover, community engagement is essential since it allows for community empowerment, which serves the state's tourism development. Ultimately, to establish itself as an emerging destination in Asia, Sarawak's state government, authorities, and stakeholders must demonstrate the capabilities to come together and support the local tourism industry (Ting et al., 2021). 


\section{Practical Implications for Asian Businesses}

In the Asian context, the current study underscores the importance of Chinese tourists as a main contributing group to national income, on account of their booming outbound travel activities. Based on the present findings, Chinese travelers intend to visit, revisit, and stay longer in a destination for different push and pull purposes, including destination image, motivation, infrastructure, and cultural barriers. These factors should be examined closely and improved upon to attract inbound tourists to the destination. Apart from that, local and international authorities (e.g., travel agents, transportation agencies, and tour operators) need to collaborate to develop attractive travel packages that appeal to Chinese tourists. The advancement of telecommunications in tourism has created opportunities for various countries' national and regional tourism organizations. Hence, further exploration on the usage of integrated marketing channels to communicate with international tourists is imperative to enhance tourist engagement. In addition, the availability of accommodation facilities is a significant factor driving international tourists' visit intentions at an emerging destination. Therefore, accommodation facilities with various options should be presented, especially since international tourists no longer invariably choose to stay in hotels, but are expanding their options to places like homestays, inns, guesthouses, and so on.

When traveling in Asia, infrastructure like taxis and public transportation are the most common means of transport for Chinese tourists. For instance, in Japan, a country with a well-developed public transportation system, 80 percent of Chinese tourists use public transportation; in Thailand, where the public transportation system is less developed, Chinese tourists prefer to use taxis. Hence, Sarawak's local authorities must ensure that logistics and transportation development is upgraded from time to time, especially by collaborating with other regional trading partners to develop a larger consortium. For example, local airlines could propose standardized pricing for ASEAN tickets at an agreed price, so that tourists can fly to all regional destinations without paying more. Besides, collaborations can work towards a centralized destination theme that encourages multi-country travel, ranging from sports destinations to leisure ones.

Despite its valuable findings, this study is not without limitations, particularly because it was conducted before the Covid-19 pandemic. The impact of the pandemic on Chinese tourists' visit intentions to emerging destinations thus calls for more investigation in the future. In fact, the proposed explanatory framework in this study can be used to examine the push and pull factors of countries' tourism in the postpandemic context and when borders begin to open for travel. It could be adopted as a basis for future investigation to validate contextual and facilitating factors and thus elucidate tourists' decision-making and intention to visit an emerging destination.

To sum up, based on the case of Sarawak, this study offers some insights into the sustainable tourism development of emerging destinations in Asia. The key factors that attract Chinese tourists are assessed in three distinct forms of visit intention. Although travel and tourism activities are badly affected by the COVID-19 pandemic, it is important that tourism officials and professionals, such as destination marketing organisations and (online) travel agencies, take the opportunity to reset and restrategise to improve their tourism offerings not only to attract tourists to visit, but also revisit and spend longer time at the target destination. 


\section{Acknowledgements}

This paper is part of a research conducted under Grant No: I05/SpFRI/1428/16/5, entitled "Developing A Destination-based Touring Experience Model: A Pragmatic Inquiry into Touring Experience in Sarawak from the Perspectives of Malaysians, Neighboring and Distant Countries"

\section{References}

Ajzen, I., (1991). The theory of planned behavior. Organizational behavior and human decision processes, vol. 50, no. 2, pp.179-211.

Baniya, R. and Paudel, K., (2016). An analysis of push and pull travel motivations of domestic tourists in Nepal. Journal of Management and Development Studies, vol. 27, pp.16-30.

Basit, T., (2003). Manual or electronic? The role of coding in qualitative data analysis. Educational research, vol. 45, no. 2, pp.143-154.

Bindu, T. and Kanagaraj, C., (2013). A study on international tourist's satisfaction with tourism services in Kerala. Life Science Journal, vol.10, no. 9s, pp.177-185.

Braun, V. and Clarke, V., (2006). Using thematic analysis in psychology. Qualitative research in psychology, vol. 3, no. 2, pp.77-101.

Çelik, S. and Dedeoğlu, B.B., (2019). Psychological factors affecting the behavioral intention of the tourist visiting Southeastern Anatolia. Journal of Hospitality and Tourism Insights, vol. 2 no. 4 , pp. 425-450. https://doi.org/10.1108/JHTI-01-2019-0005

Chandra, Y. and Shang, L., (2017). An RQDA-based constructivist methodology for qualitative research. Qualitative Market Research: An International Journal, vol. 20, no. 1, pp. 20112.

Chang, H.M., Chou, C.L. and Wu, C.L. (2017), "Destination tourism information sources, trip quality and behavioral intentions for Island tourists", International Journal of Information Technology and Business Management, vol. 60, no. 1, pp. 22-43.

Chen, J.V., Htaik, S., Hiele, T.M. and Chen, C., (2017). Investigating international tourists' intention to revisit Myanmar based on need gratification, flow experience and perceived risk. Journal of Quality Assurance in Hospitality \& Tourism, vol. 18, no. 1, pp.25-44.

Chin, C.H., Law, F.Y., Lo, M.C. and Ramayah, T., (2018). The Impact of Accessibility Quality and Accommodation Quality on Tourists' Satisfaction and Revisit Intention to Rural Tourism Destination in Sarawak: The Moderating Role of Local Communities' Attitude. Global Business and Management Research, vol. 10, no. 2, pp.115-127.

Corbin, J., Strauss, A., and Strauss, A. L. (2014). Basics of qualitative research. Thousand Oaks, CA: Sage Publications.

Creswell, J.W. and Poth, C.N., (2016). Qualitative inquiry and research design: Choosing among five approaches. Sage publications.

Dai, B., Jiang, Y., Yang, L. and Ma, Y., (2017). China's outbound tourism-Stages, policies and choices. Tourism Management, vol. 58, pp.253-258.

Dolinting, E.E., Yusof, A. and Soon, C.C., (2015). Application of push \& pull theory in Island sport tourism: A study of Sipadan Island, Sabah. Journal of Physical Education and Sport, vol. 15, no. 2, pp.295.

Esu, B.B. and Ebitu, E., (2010). Promoting an emerging tourism destination. Global Journal of Management and Business Research, vol. 10, no. 1.

Fam, S.F., Dora, M.T., Othman, N.A., Azmi, F.R., Musa, H., Mohamed Azim, A.M., Norman, H. and Abdul Shuib, M.F.I., (2017). Why Tourists Visit Melaka. In Proceedings of 2017 China Marketing International Conference (CMIC 2017), Marketing Strategy in the Sharing Economy: Localization and Globalization, China (pp. 785-807).

Fam, K.S., Ting, H., Tan, K.L., Hussain, K. and Cheah, J.H., (2020). Does it matter where to run? Intention to participate in destination marathon. Asia Pacific Journal of Marketing 
and Logistics, vol. 32 no. 7, pp. 1475-1494. https://doi.org/10.1108/APJML-12-20190737

Guion, L.A., Diehl, D.C. and McDonald, D., (2011). Triangulation: Establishing the validity of qualitative studies. EDIS, vol. 2011, no. 8, pp.3-3.

Harvey, J. and Powell, J., (2020). Factors influencing the implementation of self-management solutions in healthcare: an interview study with NHS managers. British Journal of Healthcare Management, vol. 26, no. 3, pp.61-70.

Hudson, S. and Thal, K., (2013). The impact of social media on the consumer decision process: Implications for tourism marketing. Journal of Travel \& Tourism Marketing, vol. 30, no. 1-2, pp.156-160.

Joffe, H. (2012), "Thematic analysis", in Harper, D. and Thompson, A.R. (Eds), Qualitative Research Methods in Mental Health and Psychotherapy: A Guide for Students and Practitioners, John Wiley \& Sons, Hoboken, New Jersey, pp. 209-223.

Khan, A.H., Haque, A. and Rahman, M.S., (2013). What makes tourists satisfied? An empirical study on Malaysian Islamic tourist destination. Middle-East Journal of Scientific Research, vol. 14, no. 12, pp.1631-1637.

Khan, M.J., Chelliah, S. and Ahmed, S. (2017), "Factors influencing destination image and visit intention among young women travellers: role of travel motivation, perceived risks, and travel constraints", Asia Pacific Journal of Tourism Research, vol. 22, no. 11, pp. 1139-1155.

Khuong, M.N. and Nguyen, P.A., (2017). Factors affecting tourist destination satisfaction and return intention-a study in Ho Chi Minh City, Vietnam. Journal of Economics, Business and Management, vol. 5, no. 2, pp.95-102.

Kim, S., Ao, Y., Lee, H. and Pan, S., (2012), January. A study of motivations and the image of Shanghai as perceived by foreign tourists at the Shanghai EXPO. Journal of Convention \& Event Tourism, vol. 13, no. 1, pp. 48-73.

King, V.T., (2017). Introduction to the Special Issue: Emerging tourisms and tourism studies in Southeast Asia. Asian Journal of Tourism Research, vol. 2, no. 2, pp.1-32.

Kurasaki, K.S (2000). Intercoder reliability for validating conclusions drawn from open-ended interview data. Field Methods, vol. 12, no. 3, pp. 179-194.

Lai, I.K.W., Hitchcock, M., Lu, D. and Liu, Y., (2018). The influence of word of mouth on tourism destination choice: Tourist-resident relationship and safety perception among Mainland Chinese tourists visiting Macau. Sustainability, vol. 10, no. 7, pp.2114.

Li, F., Wen, J. and Ying, T., (2018). The influence of crisis on tourists' perceived destination image and revisit intention: An exploratory study of Chinese tourists to North Korea. Journal of Destination Marketing \& Management, vol. 9, pp.104-111.

Mandal, P. and Vong, J. eds., (2016). Development of tourism and the hospitality industry in Southeast Asia. Springer.

Maxfield, M.G. and Babbie, E.R., (2014). Research methods for criminal justice and criminology. Cengage Learning.

Meleddu, M., Paci, R. and Pulina, M., (2015). Repeated behaviour and destination loyalty. Tourism Management, vol. 50, pp.159-171.

Natow, R.S., (2020). The use of triangulation in qualitative studies employing elite interviews. Qualitative Research, vol. 20, no. 2, pp.160-173.

Nugroho, A., (2017). ASEAN tourism marketing communication attribute: An exploratory research at Goaseantv. European Research Studies Journal, Volume 20, no. 3A, pp. 383-395.

Perry, C., (1998). Processes of a case study methodology for postgraduate research in marketing. European Journal of Marketing, vol. 32, no. 9/10, pp. 785-802.

Piuchan, M., Chan, C.W. and Kaale, J., (2018). Economic and socio-cultural impacts of Mainland Chinese tourists on Hong Kong residents. Kasetsart Journal of Social Sciences, vol. 39, no. 1, pp.9-14.

Polit, D. F., Beck, C. T. (2012). Nursing research: Principles and methods. Philadelphia, PA: Lippincott Williams \& Wilkins.

Prayag, G., Chen, N. (Chris) and Chiappa, G.D. (2018), "Domestic tourists to Sardinia: 
motivation, overall attitude, attachment, and behavioural intentions", Anatolia, Vol. 29 No. 1, pp. 84-97.

Rosyidi, M.I., (2018). The characteristics of Chinese tourists in Indonesia and its performance in 2013- 2017. Binus Business Review, vol. 9, no. 2, pp.145-152.

Saldaña, J. (2021), The Coding Manual for Qualitative Researchers, Sage Publications, Thousand Oaks, CA.

Seow, A.N., Choong, Y.O., Moorthy, K. and Chan, L.M., (2017). Intention to visit Malaysia for medical tourism using the antecedents of Theory of Planned Behaviour: A predictive model. International Journal of Tourism Research, vol. 19, no. 3, pp.383393.

Sivadasan, F., (2017). Bird-watching and wildlife tours: alternative tourism escalates niche tourism markets? Aptness of Sarawak state, Malaysia. Journal of Tourism, vol. 18, no. 2, p.31.

Strauss, A. and Corbin, J.M., (1997). Grounded theory in practice. Sage Publications. Thousand Oaks, California.

The World Bank (2014) World Data Bank - world development indicators. Accessed 18 Aug 2014. http://databank.worldbank.org/data/views/reports/tableview.aspx?isshared=true

Theobald, W., 1995. Global Tourism, Butterworth-Heinemann. Times of Malta (2013) "Malta's Tourism Policy \& Hondoq" Sunday, January 27, 2013,19:30 by Jane Carr, Qala [ Site: http://www.timesofmalta.com/articles/view/20130127/letters/Malta-s-tourismpolicyand Hondoq.454943].

Ting, H., Fam, K.S., Hwa, J.C.J., Richard, J.E. and Xing, N., (2019). Ethnic food consumption intention at the touring destination: The national and regional perspectives using multigroup analysis. Tourism Management, vol. 71, pp.518-529.

Ting, H., Lim, T.Y., de Run, E.C., Koh, H. and Sahdan, M., (2018). Are we Baby Boomers, Gen X and Gen Y? A qualitative inquiry into generation cohorts in Malaysia. Kasetsart Journal of Social Sciences, vol. 39, no. 1, pp.109-115.

Ting, H., Morrison, A.M., Leong, C.M., Kumarusamy, R. and Leong, Q.L. (2021). Responsibility, Responsible Tourism and Our Response. Journal of Responsible Tourism Management, vol. 1, no. 2, pp.1-9.

Trupp, A. and Dolezal, C., (2020). Tourism and the sustainable development goals in Southeast Asia. Austrian Journal of South-East Asian Studies, vol. 13, no. 1, pp.1-16.

Tsang, E.W., (2014). Case studies and generalization in information systems research: A critical realist perspective. The Journal of Strategic Information Systems, vol. 23, no. 2, pp.174-186.

UNWTO. (2019). International tourism highlights 2019. Retrieved from https://www.eunwto.org/doi/ pdf/10.18111/9789284421152.

Wong, M., Cheung, R. and Wan, C. (2013), "A study on traveler expectation, motivation and attitude", Contemporary Management Research, vol. 9, no. 2, pp. 169-186

World Tourism Organization. (2017). Why Tourism. Retrieved July 20, 2018 from http://www2.unwto.org/content/why-tourism

WTTC. (2019). Travel \& tourism economic impact 2019: Southeast Asia. London: World Travel and Tourism Council.

Yousefi, M. and Marzuki, A., (2015). An analysis of push and pull motivational factors of international tourists to Penang, Malaysia. International Journal of Hospitality \& Tourism Administration, vol. 16, no. 1, pp.40-56.

Yu, C., (2013). The significant capacity of social media in city tourism marketing. Meadin website. $<$ http://info. meadin. com/FengyunMan/2013-2-1/132127190. shtml> Accessed, 20, p.13.

Zhou, L. and Wang, T., (2014). Social media: A new vehicle for city marketing in China. Cities, vol. 37, pp.27-32. 